\title{
$\beta$-菱面体ボロン結晶における 赤外分光スペクトルの同位体組成依存性
}

\author{
野木直行*† 田中 知* 野田哲二** \\ *東京大学大学院システム量子工学専攻 \\ **金属材料技術研究所
}

J. Japan Inst. Metals, Vol. 63, No. 9 (1999), pp. 1157-1160

Papers from JIM Spring Meeting (1999)

\section{Isotopic Composition Dependence on Infrared Reflectance Spectra of $\beta$-Rhombohedral Boron Crystals}

\author{
Naoyuki Nogi*t†, Satoru Tanaka* and Tetsuji Noda** \\ *Department of Quantum Engineering and Systems Science, The University of Tokyo, Tokyo 113-8656 \\ ${ }^{*}$ National Research Institute for Metals, Tsukuba 305-0047
}

We have measured infrared-reflectance spectra at room temperature of isotopically $\left({ }^{10} \mathrm{~B}\right.$ or $\left.{ }^{11} \mathrm{~B}\right)$ enriched, blended $\left(42\right.$ at $\%{ }^{10} \mathrm{~B}$ and 58 at $\left.\%{ }^{11} \mathrm{~B}\right)$ and natural $\left(19.8\right.$ at $\%{ }^{10} \mathrm{~B}$ and 80.2 at $\left.\%{ }^{11} \mathrm{~B}\right) \quad \beta$-rhombohedral boron. For the $A_{2 u}$ and $E_{u}$ modes of ${ }^{10} \mathrm{~B},{ }^{11} \mathrm{~B}$ and natural boron which were observed with light polarization parallel or perpendicular to the $c$-axis, the mode frequency $\omega$ of each symmetry changed with the classical harmonic approximation.

The mode frequency of inter- or several intra-icosahedral modes of an isotopically mixed crystal was lower than expected frequency from the harmonic model. It is possible that isotopic disorder-induced frequency shifts, which is an anharmonic effect, is obtained by using isotope-modified samples.

(Received April 26, 1999; In Final Form August 24, 1999)

\begin{abstract}
Keywords: phonons, isotope effect, $\beta$-rhombohedral boron, infrared reflectance spectra, $A_{2 u}$-mode, $E_{u}$-mode, isotopic disorder, anisotropy
\end{abstract}

\section{I．緒訔}

結晶中の同位体組成比を変觉ることによって，主に格子振 動, すなわちフォノン周波数の相違に起因する同位体効果が 現れる(1)-(3)。例宎ば天然のゲルマニウム単結晶中には暴な る安定同位体が数種類含まれているが，これらのどれか 1 種類を高濃縮することにより，熱伝導度が上昇する報告がな されている(4).さらに，同位体組成比を変えた材料では，格 子振動の周波数が，平均同位体質量に依存するのみでなく， 単位胞中の同位体種が，どのサイトを占有するかによって生 じる同位体無秩序 (isotopic disorder) 飞も影響されらるとい ら報告も存在する(5)-(9).

これまでに我々は，軽元素であり，自然界に执いては2 種類の同位体 $\left({ }^{10} \mathrm{~B}: 19.8 \%,{ }^{11} \mathrm{~B}: 80.2 \%\right)$ のからなるボロン 固体結晶の格子振動に及洨す同位体効果に注目をし，これら の同位体比を調整した $\beta$-菱面体晶相ボロンの単結晶育成を

† 1999年 3 月31日日本金属学会春季大会に抬いて発表

胡東京大学大学院生(Graduate Student, The University of Tokyo)
行ってきた ${ }^{(10)} . \beta-\mathrm{B}_{105}(R \overline{3 m})$ の光学フォノン (optical mode) に関して，群論にもとづく分類では，波数べクトル: $k=0$ で許される既約表現は以下のよらである(11)-(14).

$$
\Gamma_{k=0}=31 \mathrm{~A}_{2 \mathrm{u}}+52 \mathrm{E}_{\mathrm{u}}+31 \mathrm{~A}_{1 \mathrm{~g}}+51 \mathrm{E}_{\mathrm{g}}
$$

ここで， $\mathrm{A}_{2 \mathrm{u}}$ と $\mathrm{E}_{\mathrm{u}}$ はそれぞれ赤外活性モードであり $\mathrm{A}_{1 \mathrm{~g}}$ と $\mathrm{E}_{\mathrm{g}}$ はラマン活性モードである.

ボロン結晶については，少なくとも3 種類の多形が存在 することが知られて和り(13)-(15)，その中で，最も安定な構造 とされているのは $\beta$ - $\mathrm{B}_{105}$ である(15)-(17)，単位胞を六方晶で 表すと $a=1.0944 \mathrm{~nm}, c=2.3811 \mathrm{~nm}$ である。ボロン結晶の 単位胞中には，副格子としての正二十面体クラスタ構造が含 まれて括り，クラスタはその内外で全て共有結合により結ば れている特徴がある。

これまで，むうひとつの代表的な多形である $\alpha$-菱面体晶 相 $\left(\alpha-\mathrm{B}_{12}\right)$ と， $\beta-\mathrm{B}_{105}$ 結晶による赤外，ラマン分光研究が存 在し, 光学モ一ドの測定が行わ机てきた(11)(14)(18)(19).

しかしながら同位体濃縮或いは混合結晶を用いた $\beta-\mathrm{B}_{105}$ の格子振動の研究はなされておらず，我々は今回， ${ }^{10} \mathrm{~B}$ 濃 縮, ${ }^{11} \mathrm{~B}$ 濃䧽，天然同位体組成並びに混合結晶の 4 種類の単 結晶試料を用いて，赤外反射分光を行い，得られた赤外活性 
なモードの周波数の，同位体組成にともならずれの原因を探 ること，および各モードから得られた $\beta-\mathrm{B}_{105}$ の結合力に関 する知見を得ることを目的とした。

\section{II. 実 験 手 法}

浮遊带域溶融により，4種類の同位体組成比を变えた $\beta$ $B_{105}$ の単結晶を準備した(10). 得られた結晶の同位体組成比 は，それぞれ， ${ }^{10} \mathrm{~B}$ 濃縮 ( ${ }^{10} \mathrm{~B}: 93.2$ at $\%,{ }^{11} \mathrm{~B}: 6.4$ at $\left.\%\right),{ }^{11} \mathrm{~B}$ 濃縮 (12B : 99.0 at \% , ${ }^{10} \mathrm{~B}: 1.0$ at \%)，天然同位体組成 ${ }^{10} \mathrm{~B}$ : 19.8 at\%, ${ }^{11} \mathrm{~B}: 80.2$ at $\left.\%\right)$ および同位体混合 $\left({ }^{10} \mathrm{~B}: 41.6\right.$ at $\%$, ${ }^{11} \mathrm{~B}: 58.4 \mathrm{at} \%$ ) である。前述の単結晶口ッドから，X線ラウ エ法によって，2 種類の面方位 $(10 \overline{1} 0)$ 特よび(0001)を有す る試料を切り出した。切り出された試料サイズは，それぞれ

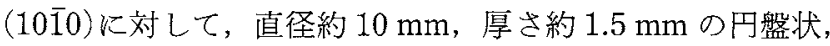
(0001) 面は約 $7 \mathrm{~mm} \times 10 \mathrm{~mm}$ の角型状である. 試料の片面 は鏡面研磨されている. 赤外反射分光はフーリ工変換赤外分 光器 (JIR-7000)を用いて, 室温で行われた. 測定波数領域

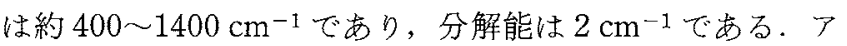
ルミニウム或いは金蒸着膜を参照信号に使用した。

\section{III. 結 果と考察}

Fig. 1 は ${ }^{10} \mathrm{~B}$ 濃縮， ${ }^{11} \mathrm{~B}$ 濃縮，天然 B 並びに混合 ${ }^{10} \mathrm{~B}$ : $42 \%) の 4$ 種類の $\beta-\mathrm{B}_{105}$ 結晶の赤外反射スペクトルである. スペクトルは，六方晶における $c$ 軸に平行执よび垂值な 2 種 類の偏光，すなわら光電場ベクトル $\boldsymbol{E}_{/ /}$㟧よび $\boldsymbol{E}_{\perp}$ にるる のである。 $\boldsymbol{E}_{/ /}$には赤外活性モードの $\mathrm{A}_{2 \mathrm{u}}$ が， $\boldsymbol{E}_{\perp}$ には $\mathrm{E}_{\mathrm{u}}$ モ ードが対応する，同位体組成の相違に伴い，周波数シフトが み。

今回得られた赤外反射スペクトルは，文献(11)に和ける， 古典的解析による天然 $\beta-\mathrm{B}_{105}$ の赤外活性なフォノン分散関 係にしたがって，ピークの蠻を行った。

Fig. 2 は質量数の平方根の逆数すなわち $1 / \sqrt{M}$ 《対する 波数: $k(=\omega / 2 \pi c)$ の実験值との関係である.

一般に古典調和振動子モデルでは, 角周波数： $\omega$ は以下 のように表される。

$$
\omega(=2 \pi c k)=\sqrt{K / M}
$$

ここで $k, K$ 执よび $M$ はそれぞれ波数，結合力定数和よび質 点の質量，さらに $c$ は光速である.式 (1)にもとつくに执い て, 力定数 : $K$ が一定, すなわら結合力定数が同位体質量 に依存しない場合, 格子振動は調和振動子的であることを示 す。 ${ }^{11} \mathrm{~B}$ の波数(実験値)を基点とした場合， ${ }^{10} \mathrm{~B}$ 濃縮結晶の フォノン周波数の実験值は，調和近似から予想される $\left.\omega\left({ }^{10} \mathrm{~B}\right)=\omega_{\text {exp eri. }}\left({ }^{11} \mathrm{~B}\right) \cdot \sqrt{M\left({ }^{11} \mathrm{~B}\right) / M\left({ }^{10} \mathrm{~B}\right)}=1.049 \cdot \omega_{\text {exp eri. }}{ }^{(11} \mathrm{B}\right)$ に一致し，李た同様に，天然の $\beta-\mathrm{B}_{105}$ 結晶 $\left({ }^{10} \mathrm{~B}: 19.8 \%\right) の$ 波数む，この ${ }^{11} \mathrm{~B}$ の波数と ${ }^{10} \mathrm{~B}$ の波数を両端にとった直線上 に存在した。したがって，天然 $\beta-\mathrm{B}_{105}$ 結晶：同位体組成 $\left({ }^{10} \mathrm{~B}: 19.8 \%\right.$ 特よび $\left.{ }^{11} \mathrm{~B}: 80.2 \%\right)$ に掞いては，格子振動は調
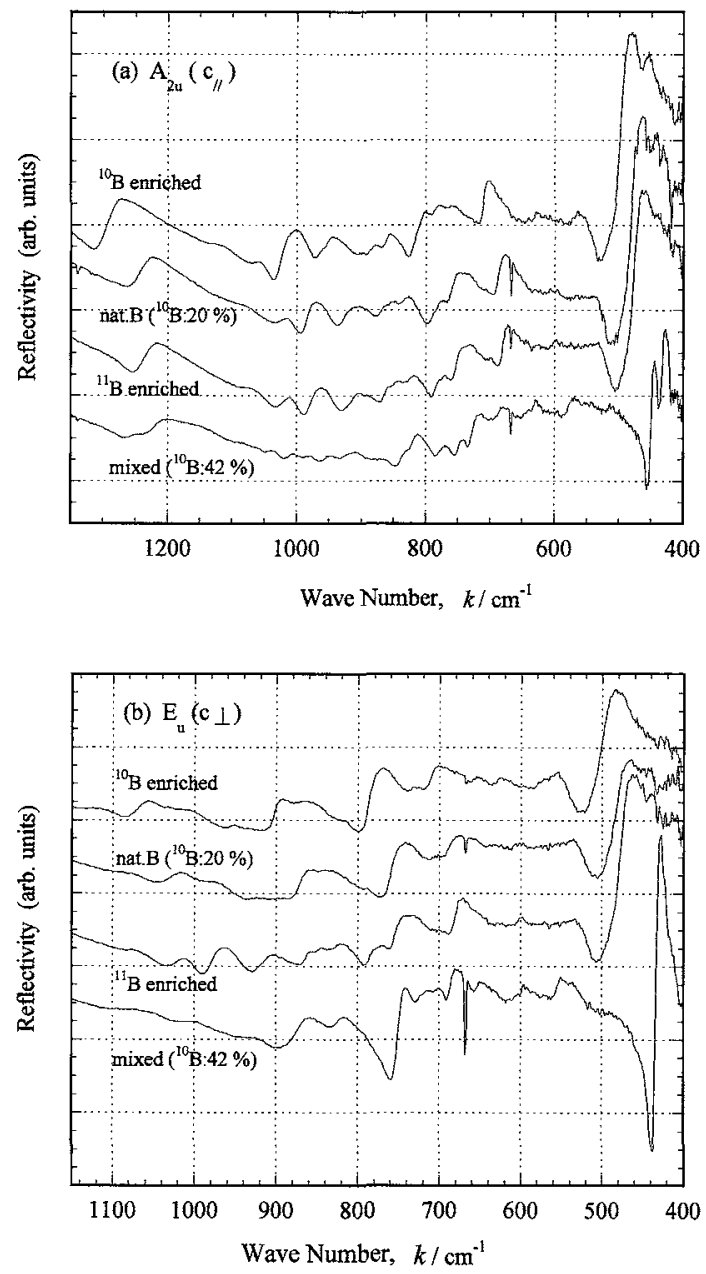

Fig. 1 Infrared-reflectance spectra of $\beta$-rhombohedral boron with an isotopic composition modified. Light polarization is parallel (a) or perpendicular (b) to the $c$-axis.

和的であり，周波数のずれの原因も平均同位体質量数のみに 低存しているとい光，それ以外の影響は忹とえどないといえ る。これより天然同位体組成比に和いては，10B(19.8\%)は， ${ }^{11} \mathrm{~B}(80.2 \%)$ 飞対して，むしろ不純物的であると解秎できる。

一方，同位体混合結晶 $\left(42\right.$ at $\%{ }^{10} \mathrm{~B}+58$ at $\left.\%{ }^{11} \mathrm{~B}\right)$ K括ける 波数について，特に， $1230 \mathrm{~cm}^{-1}$ 付近の単一B 原子による 振動 $\left(\mathrm{A}_{2 \mathrm{u}}\right.$ モード)，並びに単位胞中の副格子である正二十面 体間のモードである，420 480 $\mathrm{cm}^{-1}$ の振動 $\left(\mathrm{A}_{2 \mathrm{u}}, \mathrm{E}_{\mathrm{u}}\right.$ 両乇 ード)は調和的でないことを示した。また $\mathrm{E}_{\mathfrak{1}}$ モードにおい て，正二十面体間の振動汪どではないが，正二十面体内の振 動も低波数側に下がる傾向が見られた。これらのことは調和 近似が成り立たないことを示して拈り，同位体混合結晶 (42 at\% $\left.{ }^{10} \mathrm{~B}\right)$ に打いては，周波数のずれの原因は同位体質量 数の相違に加㝋，何らかの非調和効果が影響したものと判断 できる。これに関連し $\mathrm{Ge}$ 同位体の混合単結晶による実験報 告が存在する(6)-(8)。それによれば，調和的でなくなる原因 には，単位胞中で，同位体種のサイトの占め力によって，置 換型の不規則である同位体不規則 (isotopic disorder)の效果 

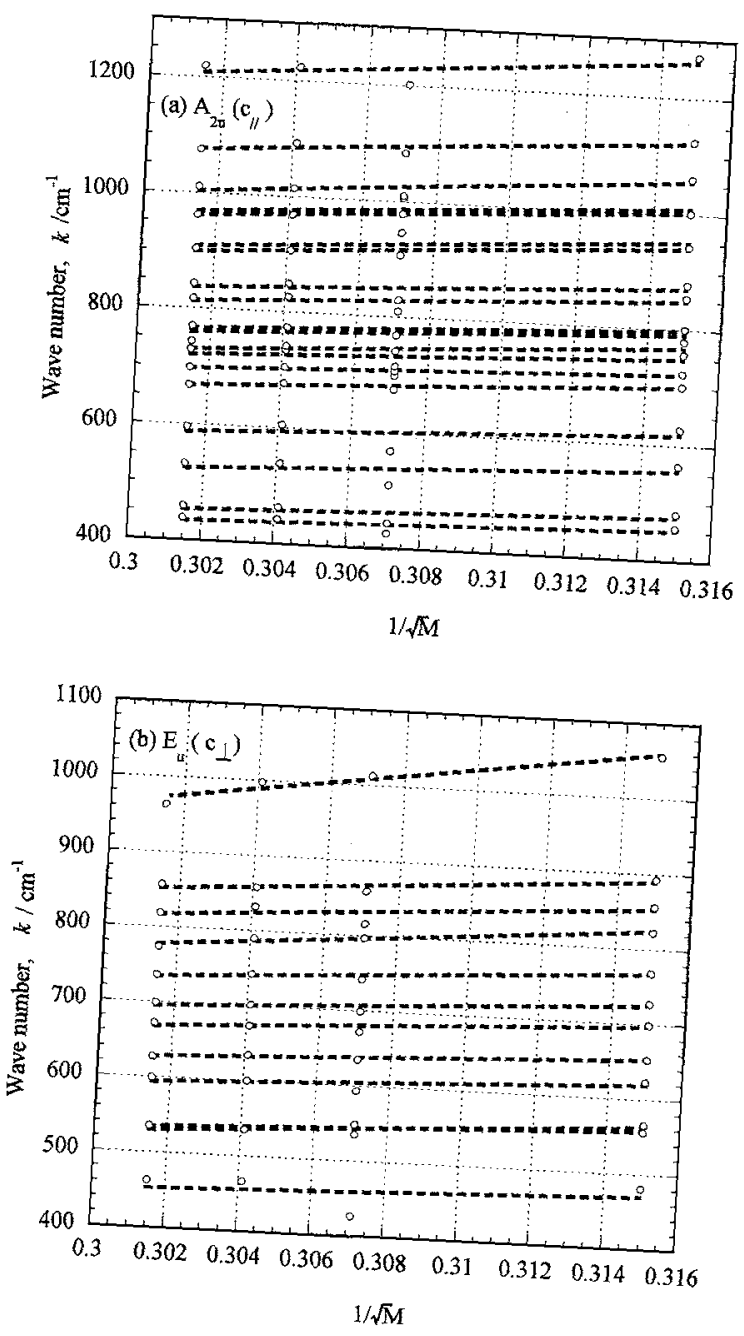

Fig. 2 Mode frequency of the $A_{2 u}$ (a) and $E_{u}$ (b) vs. the inlines represent the the mass number of $B: 1 / \sqrt{M}$. The dotted approximation. the frequency change following the harmonic

が現れることによるとされる。本研究に和いて用いたB原 子は軽元素であり ${ }^{11} \mathrm{~B} /{ }^{10} \mathrm{~B} \sim 10 \%$ と相対啠量差が大きく，2 種類の同位体の，サイトの占め方が，この非調和的な格子振 動の一因に寄与しているとい方。

また，共有結合された正二十面体間に蛙いて，この非調和 効果が顕著であることは，ボロンクラスタ固体に特有な同位 体効果である可能性すある。しかし，このことに関しては， さらに詳細なスペタトルの㛟討，或いは他の同位体混合結晶 走用いて再現泩をみることが重要である。

次に，式(1)を用いると結合加定数は， $K=-2 M^{2} \omega(d \omega)$ $d M)$ で表される。これを用いて $\beta-B_{105}$ の赤外活性モードで

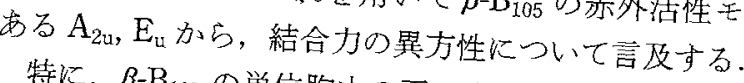

特に， $\beta-\mathrm{B}_{105}$ の単位胞中の正二十面体内の振動を表导飞一 ド(650〜1100 $\left.\mathrm{cm}^{-1}\right) k つ い て は ， B_{12}$ (準)分子の振動である F ドが分裂すること(ダビドフ分裂)によってそれぞれ 8 本の
$A_{2 \mathrm{u}}$ と $E_{\mathrm{u}}$ モドが生じること尤るをされる(12)，したがつ

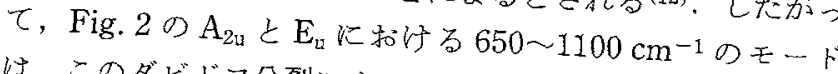
快，このダビドフ分裂によって， $\beta$-黄面体ポロンのュ=ット セル中のサブニニット二十面体の格子振動が， $c$ 軸(六方晶 系表示)に対し，乥れぞれ平行与よび垂直方向に分裂の結果 生じたモードであると解秎でき，分裂後に生じた 8 本ずり

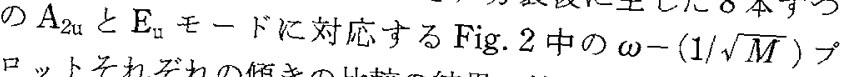
ロットそ秃ぞれの傾きの比較の結果, 結合力定数はわずかに 異方的であるといら結論に達した，興味深いことに， $\beta-B_{105}$

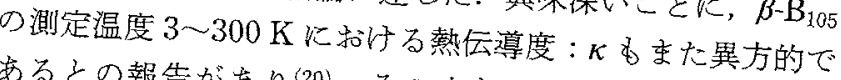
あるとの報告があり(20)，その大きさは1.1 $\leq\left(\kappa_{/} / \kappa_{\perp}\right) \leq 1.3$ である・ $\beta$ - $B_{105}$ の正二十面体内の振動袁すモード(650 $\left.1100 \mathrm{~cm}^{-1}\right)$ 力ら得ら䛢た結合力定数の異方性は，この熱厷 導度の異方性とも関連があるもの上考学られる。一方，二十 面体間の振動を表す $650 \mathrm{~cm}^{-1}$ 以下の振動そードに执いては 缥结等しかった。

\section{N. まと め}

${ }^{10} \mathrm{~B}$ 濃縮 $\left.{ }^{10} \mathrm{~B}: 93.2 \%,{ }^{11} \mathrm{~B}: 6.4 \%\right),{ }^{11} \mathrm{~B}$ 濃縮 $\left({ }^{11} \mathrm{~B}: 99.0 \%\right.$ $\left.{ }^{10} \mathrm{~B}: 1.0 \%\right)$, 天然同位体組成 $\left({ }^{10} \mathrm{~B}: 19.8 \%,{ }^{11} \mathrm{~B}: 80.2 \%\right)$ 去 よび同位体混合 $\left({ }^{10} \mathrm{~B}: 41.6 \%,{ }^{11} \mathrm{~B}: 58.4 \%\right) の 4$ 種類の同位 体組成此を变えた $\beta-\mathrm{B}_{105}$ の単結晶による赤外反射スぺクト ルを穻温で測定した，その結果，同位体混合結晶を除いた 3 種類の試料の赤外活性 $A_{2 \mathrm{u}}, \mathrm{E}_{\mathrm{u}}$ 雨モードは $\mathrm{B}$ 原子の質量数の 平方根の逆数に比例，寸なわ方調和近似が成り立った。同位 体湦合結晶に衿いては，非調和的なモードが存在し，これに ついては 2 種類の同位体のニニットセル中のサイト占有の 仕方が影響しているとい点る。さらに正二十面体内の振動を 表すモード $\left(650 \sim 1100 \mathrm{~cm}^{-1}\right)$ より得られた結合力定数の此 較から， $\beta-\mathrm{B}_{105}$ の結合力はわずかではあるが等方的でないと 考党与机る。

\section{文献}

(1) E. E. Haller: J. Appl. Phys., 77(1995), 2857-2878

(3) 野田哲二：金属，7(1993)，32-37. 588 P. Zhernov, A. V. Inyusikinski, E. Gmelin, M. Cardona, A Itoh and E. E. Haller: Phikin, A. Taldenkov, V. I. Ozhogin, K.

(5) H. D. Fuchs, C. H. Grein M Rev., B56(1997), 9431-9447. and E. E. Haller: Solid State Commun, W. L. Hansen, K. Itoh

(6) J. M. Zhang, M. Giehler, A Goebel T, 82 (1992), 225-228. Haller and K. Itoh: Phys, A. Goebel, T. Ruf, M. Cardona, E. E.

(7) H. D. Fuchs, C. H. Grein Rev., B57 (1998), 1348-1718. Rev., B45 (1992), 4065-4070. Bauer and M. Cardona: Phys.

(8) P. H. Etche Pintschovious, N. H. D. Fuchs, J. Weber, M. Cardona, L. B48(1993), 12661-12671. Itoh and E. E. Haller: Phys. Rev., Hansen, E. C. Grein, H. C. Thomsen, M. Cardona, W. L. 4835-4852.

(10) N. Nogi, T. Hirano, K. Honda, S. Tanaka and T Noda: J. Surf Analys., 4(1998), 280-283. 
(11) H. Binnenbruck and H. Werheit: Z. Naturforsch., 34a(1979), 787-798.

(12) H. Binnenbruck and H. Werheit: J. Less-Comm. Met., 47(1976), 91-95.

(13) H. Werheit and H. Haupt: 10th Int. Sym. of Boron, Borides and Related Compounds, Ed. by D. Emin, T. L. Aselage, A. C. Switendick, B. Morosin and C. L. Beckel, American Institute of Physics, (1991), 355-359.

(14) W. Richter, A. Hausen and H. Binnenbruck: Phys. Stat. Sol., (b) 60 (1973) , 461-465.
(15) B. F. Decker and J. S. Kasper: Acta Cryst., 12(1959), 503506.

(16) B. Callmer: Acta Cryst., B33(1977), 1951-1954.

(17) P. Runow: J. Mat. Sci., 7 (1972), 499-511.

(18) W. Richter and K. Ploog: Phys. Stat. Sol., (b) 68(1975), 201205.

(19) W. Richter, W. Weber and K. Ploog: J. Less-Comm. Met., $47(1976), 85-90$

(20) G. A. Slack, D. W. Oliver and F. H. Horn: Phys. Rev., B4 (1971), 1714-1719. 